\title{
SABERES DOCENTES: AS POLIITICAS DE RECONHECIMENTO DE SABERES DOS PROFESSORES DA EDUCAC̦ÃO PROFISSIONAL NO BRASIL
}

\author{
Natália Valadares Lima* \\ Universidade Federal de Minas Gerais (UFMG), Belo Horizonte - MG, Brasil \\ Daisy Moreira Cunha** \\ Universidade Federal de Minas Gerais (UFMG), Belo Horizonte - MG, Brasil
}

RESUMO: Esta comunicação objetiva discutir o desenvolvimento e implementação de políticas voltadas para o reconhecimento de saberes dos professores do Ensino Básico, Técnico e Tecnológico. Inicialmente, apresentamos os marcos regulatórios do processo de Reconhecimento de Saberes e Competências (RSC) desses professores aprofundando-nos, por meio da análise de documentos e regulamentações, na forma como o RSC tem sido implementado em uma instituição de educação profissional de Minas Gerais. Para discutir sobre os saberes construídos no/pelo trabalho, recorremos ao aporte da ergologia, em especial aos trabalhos de Durrive e Schwartz (2007), Schwartz $(1998,2010)$ e Trinquet (2010). No âmbito dos saberes docentes, realizamos pesquisa bibliográfica abarcando autores, como Schön (1992), Tardif (2002), Therrien (2001), entre outros, que tratam sobre especificidade desses saberes e sua importância para a docência. Por fim, apontamos para a necessidade de se pensar como as políticas de reconhecimento de saberes docentes vêm se constituindo e quais saberes elas valorizam.

Palavras-chave: Saberes docentes. Educação Profissional. Reconhecimento de saberes.

\section{TEACHING KNOWLEDGE: POLICIES FOR TEACHER'S KNOWLEDGE RECOGNITION IN BRAZILIAN VOCATIONAL EDUCATION}

ABSTRACT:This communication discusses the development and implementation of policies for the recognition of knowledge of Basic Technical and Technological Education teachers. Initially, we present the regulatory

\footnotetext{
"Doutoranda em Educação pela Faculdade de Educação da Universidade Federal de Minas Gerais. Mestra em Educação pela Faculdade de Educação da UFMG. Pesquisadora do Núcleo de Estudos sobre Trabalho e Educação da UFMG. Técnico-Administrativa em Educação no Centro Federal de Educação Tecnológica de Minas Gerais. E-mail: < natvlima@gmail.com>.

" Doutora em Filosofa (Epistemologia e História da Filosofa) pela Aix-Marseille Université, PósDoutorado pelo Conservatoire National des Arts et Métiers (CNAM/Paris). Professora Associada do Programa de PósGraduação em Educação da FaE/UFMG. Pesquisadora do Núcleo de Estudos sobre Trabalho e Educação. E-mail: < daisycunhaufmg@gmail.com >.
} 
framework of the process of Knowledge and Competence Recognition (RSC) of these teachers, exploring the way that RSC has been implemented in a vocational education institution through analysis of documents and regulations. In order to discuss the knowledge built through he work, we used ergology contributions, especially the works of Durrive and Schwartz (2007), Schwartz $(1998,2010)$ and Trinquet (2010). To address the theme "teaching knowledge", we carried out a bibliographical research with authors such as Schön (1992), Tardif (2002), Therrien (2001), among others, that wrote about the specificity of these knowledge and its importance for teaching. Finally, we point out the need to think about how teacher knowledge recognition's policies have been constituted and what kinds of knowledge they value.

Keywords: Teachers knowledge. Vocational Education. Knowledge recognition.

\section{INTRODUCุ̃̃O}

O presente trabalho apresenta discussões oriundas da pesquisa de doutorado, intitulada Experiência, saberes e formação: reconbecimento de saberes dos professores do ensino básico, técnico e tecnológico. Nessa comunicação, temos como objetivo problematizar o desenvolvimento e implementação de políticas públicas voltadas para o reconhecimento de saberes e competências dos professores da carreira do Ensino Básico, Técnico e Tecnológico (EBTT). Assim, apresentamos as políticas recentes voltadas para o reconhecimento dos saberes desses professores e, tendo o aporte da ergologia, discutimos a construção de saberes no trabalho e as especificidades dos saberes docentes.

Nos dias atuais, constata-se um aumento das discussões que enfatizam a necessidade de criação de estratégias que valorizem as aprendizagens realizadas pelos sujeitos ao longo de sua vida. Nesse entendimento, há uma ampliação do tempo e do espaço educativo para além das formas institucionalizadas de educação. Reconhece-se que a educação se estende a diferentes contextos sociais, tal como o trabalho, atividades comunitárias e a vida familiar, que, por sua vez, constituem-se como lócus de produção de saberes. Além disso, a aprendizagem não está mais delimitada ao tempo de escolarização formal, se considerando (e exigindo) que ela acontece continuamente no decorrer da vida do indivíduo.

Em consonância com esse discurso, ampliam-se as demandas por iniciativas que busquem desenvolver metodologias que viabilizem o reconhecimento social de aprendizagens construídas na/pela experiência (ALCOFORADO, 2008; MORAES; NETO, 2005). Assim sendo, diversos autores constatam, no decorrer das últimas três décadas, que diferentes países vêm elaborando sistemas voltados para a avaliação 
e o reconhecimento de saberes da experiência (BJØRNÅVOLD, 2009; YOUNG; ALLAIS, 2013; JARVIS, 2014; entre outros).

Essas ações são respaldadas por orientações emitidas por agências internacionais a respeito da educação e formação de adultos (ALCOFORADO, 2008). Nesse âmbito, destaca-se a atuação da Organização das Nações Unidas para a Educação, Ciência e Cultura (UNESCO), que, por meio das Conferências Internacionais sobre Educação de Adultos, ${ }^{1}$ especialmente daquela realizada no ano de 1998, recomenda a seus Estados membros a elaboração de políticas públicas de validação e certificação de saberes resultantes de diferentes tipos de experiência (UNESCO, 1999). Somado a isto, documentos publicados por agências internacionais voltadas para o desenvolvimento econômico dos países, tal como a Organização para a Cooperação e Desenvolvimento Econômico (OCDE) e o Banco Mundial, reforçam a importância da formação profissional continuada para o aumento do potencial de produção dos países, em um contexto de modernização da produção (ALCOFORADO, 2008; AUTORA, 2015).

Nesse cenário, o governo brasileiro vem desenvolvendo e implementado políticas públicas que procuram avaliar e certificar os saberes dos trabalhadores, independentemente de sua inserção em rotas de formação profissional institucionalizadas.

Um marco das ações governamentais nesse sentido foi a promulgação da Lei de Diretrizes e Bases da Educação (LDBEN) no ano de 1996 (Lei 9.394/1996). Já em seu artigo primeiro a lei apresenta um conceito ampliado de educação, definindo que esta "[...] abrange os processos formativos que se desenvolvem na vida familiar, na convivência humana, no trabalho, nas instituições de ensino e pesquisa, nos movimentos sociais e organizações da sociedade civil e nas manifestações culturais" (BRASIL, 1996). Em consonância com essa noção de educação, o artigo 41 da referida lei determina que "o conhecimento adquirido na educação profissional, inclusive no trabalho, poderá ser objeto de avaliação, reconhecimento e certificação para prosseguimento ou conclusão de estudos" (BRASIL, 1996), respaldando a criação de políticas públicas voltadas para a certificação profissional de trabalhadores através do reconhecimento dos saberes construídos na atividade de trabalho.

A partir da LDBEN, o Estado brasileiro vem realizando discussões e promovendo programas voltados para o reconhecimento de saberes e certificação profissional. Uma das iniciativas mais recentes foi a instituição da Rede Nacional de Certificação Profissional e Formação Inicial e Continuada (Rede Certific). Esta foi formulada em 2009 com o objetivo de promover a formação e certificação 
profissional de adultos trabalhadores, e comporta, majoritariamente, certificações de profissões que requerem pouca escolarização, como pedreiros, pintores, criadores de peixe, dentre outras (LIMA, 2011).

Já no ano de 2012, por meio da lei 12.772 de 28 de dezembro de 2012, abriu-se a possibilidade para que os professores ocupantes de cargos da Carreira de Magistério do Ensino Básico, Técnico e Tecnológico insiram-se em processos de reconhecimento de saberes para fins de obtenção de Retribuição por Titulação. Nesse sentido, diferentemente da Rede Certific, a lei 12.772/2012 tem como público alvo os professores do EBTT, que, por exigência de ingresso na carreira, possuem titulação mínima de graduados e propõe a equiparação entre as atividades realizadas ao longo da vida e as titulações obtidas em nível de pós-graduação.

Diante desse quadro, o presente trabalho propõe um levantamento bibliográfico de obras que tratam sobre a problemática do reconhecimento de saberes do trabalho, especificamente dos saberes docentes, e um levantamento documental de leis, Pareceres e Resoluções que visam estabelecer políticas públicas voltadas para tal reconhecimento.

Para o desenvolvimento desta pesquisa, utilizamos o aporte teórico-metodológico dos estudos realizados nos campos da ergologia (TRINQUET, 2010; SCHWARTZ, 1998, 2010; DURRIVE; SCHWARTZ, 2007), os quais propõem uma análise da atividade de trabalho a partir da aproximação do trabalho real. Esse campo de estudo reconhece que o trabalho é um local de encontro e de confrontos nas lacunas existentes entre o prescrito e o real da atividade, e que, nesse encontro, sempre em parte singular, os trabalhadores constroem saberes para gerir o "vazio das normas" e, assim, viabilizar a execução do trabalho.

Sob esse prisma, a experiência é produtora de saberes que somente podem ser compreendidos a partir do ponto de vista do sujeito que trabalha, em um tempo e um espaço específico. Esses saberes são, em grande parte, intrínsecos ao trabalho situado e ao trabalhador que viabilizam a execução do trabalho.

\section{MARCO REGULATÓRIO DO RECONHECIMENTO DE SABERES DOS DOCENTES DA EDUCAÇÃO PROFISSIONAL}

A discussão sobre a implementação do processo de Reconhecimento de Saberes e Competências dos professores do Ensino Básico, Técnico e Tecnológico acontece juntamente ao processo de 
negociação de reestruturação da carreira de magistério EBTT, ${ }^{2}$ realizado entre os Sindicatos que representam a categoria e o Governo Federal. Tal discussão, que se inicia em 2011, fortalece-se em 2012, com a greve dos docentes das instituições de ensino federal, culminando na promulgação da Lei 12.772, de 28 de dezembro de 2012.

Esta lei estabelece em seu artigo 18, inserido no Capítulo que trata sobre a remuneração do plano de carreiras e cargos do magistério federal, que

No caso dos ocupantes de cargos da Carreira de Magistério do Ensino Básico, Técnico e Tecnológico, para fins de percepção da RT [Retribuição por Titulação], será considerada a equivalência da titulação exigida com o Reconhecimento de Saberes e Competências -RSC (BRASIL, 2012).

A Retribuição por Titulação que trata o artigo 18 constitui-se enquanto parte do vencimento dos docentes das instituições de ensino federais, composta pelo Vencimento Básico somado à Retribuição por Titulação à qual o docente fizer jus. Em alguns casos, a Retribuição por Titulação é responsável por um aumento significativo no salário dos docentes. Isso fica claro quando analisamos a composição salarial de um professor no primeiro nível da carreira EBTT no regime de Dedicação Exclusiva.

Um professor nestas condições recebe, como salário base, uma remuneração de R \$ 4.446,51. Contudo, a Retribuição por Titulação pode ultrapassar o valor do salário base do docente, quando o mesmo possui o título de doutor. Apresentamos, na Tabela 1, o impacto da Retribuição por Titulação na composição do vencimento de um docente nas condições supracitadas. A partir desses dados, podemos constatar que as leis que regulamentam a carreira dos docentes da EBTTT privilegiam a qualificação desses profissionais, seja por meio da realização de cursos de curso de pós-graduação ou por meio do processo de reconhecimento de saberes, oferecendo grandes incentivos no que diz respeito à remuneração.

Tabela 1. Impacto da Retribuição por Titulação no salário base dos docentes EBTT

\begin{tabular}{|c|c|c|c|c|c|}
\hline Classe & Nível & Aperfeiçoamento & $\begin{array}{c}\text { Especialização } \\
\text { ou RSC-I + } \\
\text { Graduação }\end{array}$ & $\begin{array}{c}\text { Mestrado } \\
\text { ou RSC-II + } \\
\text { Especialização }\end{array}$ & $\begin{array}{c}\text { Doutorado } \\
\text { ou RSC-III + } \\
\text { Mestrado }\end{array}$ \\
\hline DI & 1 & $7,72 \%$ & $12,76 \%$ & $31,43 \%$ & $52,32 \%$ \\
\hline
\end{tabular}

Fonte: Elaborado pela autora. 
Ao tratar do Reconhecimento de Saberes e Competências, a Lei 12.772/2012 estabelece três diferentes níveis para sua concessão, a saber: 1) diploma de graduação somado ao RSC-I, que equivale ao título de especialista; 2) certificado de pós-graduação lato sensu somado ao RSC-II, que se equipara ao mestrado; e 3) titulação de mestre somada ao RSC-III, que equivale ao título de doutor. Assim sendo, os docentes que obtiverem o RSC em qualquer um dos níveis, receberão Retribuição por Titulação referente ao nível superior ao de sua titulação acadêmica.

É importante ressaltar que a equivalência entre o RSC e a titulação acadêmica somente pode ser adotada para cálculo da Retribuição por Titulação, sendo que a promoção e/ou a aceleração da promoção na carreira EBTT, também regulamentadas pela lei 12.772/2012, ainda se vinculam à exigência de titulação acadêmica. Dessa forma, a promoção de um professor para Classe Titular somente poderá acontecer mediante a apresentação do título de doutor, somado à aprovação no processo de avaliação de desempenho e à elaboração de memorial das atividades desenvolvidas pelo docente ou defesa de tese acadêmica inédita.

Para a elaboração de procedimentos de concessão do RSC, a lei 12.772/2012 cria o Conselho Permanente para Reconhecimento de Saberes e Competências (CPRSC). Este Conselho é regulamentado pelo Ministério da Educação por meio da Portaria no 491, de 20 de junho de 2013, e da Portaria n ${ }^{\circ} 1.094$, de 7 de novembro de 2013. De acordo com a Portaria $n^{\circ} 491 / 2013$, compete ao CPRSC: a determinação de diretrizes e procedimentos para a concessão do RSC; a análise e homologação dos regulamentos específicos de cada Instituição Federal de Ensino para o RSC; e a orientação da supervisão do Ministério da Educação e do Ministério da Defesa sobre a concessão do RSC pelas Instituições Federais de Ensino.

A composição do CPRSC conta com representantes do governo federal, dos gestores da Rede Federal de Educação Profissional e Tecnológica, dos trabalhadores da educação federal e da comunidade em geral. Com esse arranjo o CPRSC parece contemplar a representação dos principais setores envolvidos e interessados na implementação e desenvolvimento do processo de Reconhecimento de Saberes e Competências, tentando constituir uma política que atenda às demandas da categoria em questão.

Aotratar especificamente sobreo processo de Reconhecimento de Saberes e Competências, a Portaria 491/2013 estabelece que ele 
deverá ser conduzido por uma Comissão Especial composta por docentes internos e externos à instituição do professor solicitante do RSC. É exigido que os membros da banca sejam docentes da carreira EBTT e que, no mínimo, $50 \%$ destes sejam profissionais externos à instituição. Todos os membros que compõem determinada Comissão Especial são selecionados por meio de sorteio no Banco Nacional de Avaliadores disponibilizado no Sistema Integrado de Monitoramento e Controle do MEC (SIMEC).

Já a Resolução no 01, de 20 de fevereiro de 2014, que estabelece as diretrizes para o processo de RSC, apresenta, pela primeira vez em textos legais, a definição do que se entende por Reconhecimento de Saberes e Competências. De acordo com o artigo $2^{\circ}$ :

Conceitua-se Reconhecimento de Saberes e Competências o processo de seleção pelo qual são reconhecidos os conhecimentos e habilidades desenvolvidos a partir da experiência individual e profissional, bem como no exercício das atividades realizadas no âmbito acadêmico, para efeito do disposto no artigo 18 da Lei $\mathrm{n}^{\circ}$ 12.772, de 2012 (BRASIL, 2014).

Para a discussão aqui realizada, é importante salientar que o texto da Resolução estabelece que o processo de reconhecimento deve se basear nas experiências individuais desenvolvidas ao longo da vida por cada docente, e não somente naquelas realizadas no âmbito da instituição de ensino ao qual o docente se vincula. Em consonância com essa definição, o artigo $7^{\circ}$ da Resolução coloca que o reconhecimento das atividades independe do tempo em que as mesmas foram realizadas. Diante dessas definições, a regulamentação do RSC converge com as discussões realizadas no âmbito da formação ao longo da vida e das políticas de reconhecimento de saberes, considerando que os saberes do sujeito relacionam-se com suas experiências em diferentes tempos e espaços.

Por outro lado, em uma análise dos critérios para concessão do RSC aos docentes, verificamos que a valorização da experiência profissional dos docentes, em especial a atuação em sua área de formação, concentra-se no primeiro nível do RSC, sendo que nos outros dois níveis as atividades acadêmicas são predominantes. Explicitamos, no quadro 1, a descrição das atividades a serem valorizadas no processo de RSC segundo o nível, conforme apresentadas na Resolução n ${ }^{\circ}$ 01/2014. 
Quadro 1. Atividades avaliadas no RSC

\begin{tabular}{|c|c|c|}
\hline RSC I & RSC II & RSC III \\
\hline $\begin{array}{l}\text { a) Experiência na área de } \\
\text { formação e/ou atuação do } \\
\text { docente, anterior ao ingresso } \\
\text { na Instituição, contemplando } \\
\text { o impacto de suas ações nas } \\
\text { demais diretrizes dispostas } \\
\text { para todos os níveis do RSC; }\end{array}$ & $\begin{array}{l}\text { a) Orientação do corpo } \\
\text { discente em atividades de } \\
\text { ensino, extensão, pesquisa } \\
\text { e/ou inovação; }\end{array}$ & $\begin{array}{l}\text { a) Desenvolvimento, } \\
\text { produção e transferência de } \\
\text { tecnologias; }\end{array}$ \\
\hline $\begin{array}{l}\text { b) Cursos de capacitação } \\
\text { na área de interesse } \\
\text { institucional; }\end{array}$ & $\begin{array}{l}\text { b) Participação no } \\
\text { desenvolvimento de } \\
\text { protótipos, depósitos e/ } \\
\text { ou registros de propriedade } \\
\text { intelectual; }\end{array}$ & $\begin{array}{l}\text { b) Desenvolvimento de } \\
\text { pesquisas e aplicação de } \\
\text { métodos e tecnologias } \\
\text { educacionais que } \\
\text { proporcionem a } \\
\text { interdisciplinaridade e a } \\
\text { integração de conteúdos } \\
\text { acadêmicos na educação } \\
\text { profissional e tecnológica ou } \\
\text { na educação básica; }\end{array}$ \\
\hline $\begin{array}{l}\text { c) Atuação nos diversos } \\
\text { níveis e modalidades de } \\
\text { educação; }\end{array}$ & $\begin{array}{l}\text { c) Participação em grupos } \\
\text { de trabalho e oficinas } \\
\text { institucionais; }\end{array}$ & $\begin{array}{l}\text { c) Desenvolvimento de } \\
\text { pesquisas e atividades de } \\
\text { extensão que proporcionem a } \\
\text { articulação institucional com } \\
\text { os arranjos sociais, culturais } \\
\text { e produtivos; }\end{array}$ \\
\hline $\begin{array}{l}\text { d) Atuação em comissões } \\
\text { e representações } \\
\text { institucionais, de classes e } \\
\text { profissionais, contemplando } \\
\text { o impacto de suas ações nas } \\
\text { demais diretrizes dispostas } \\
\text { para todos os níveis do RSC; }\end{array}$ & $\begin{array}{l}\text { d) Participação no } \\
\text { desenvolvimento de projetos, } \\
\text { de interesse institucional, de } \\
\text { ensino, pesquisa, extensão } \\
\text { e/ou inovação; }\end{array}$ & $\begin{array}{l}\text { d) Atuação em projetos e/ou } \\
\text { atividades em parceria com } \\
\text { outras instituições; }\end{array}$ \\
\hline $\begin{array}{l}\text { e) Produção de material } \\
\text { didático e/ou implantação de } \\
\text { ambientes de aprendizagem, } \\
\text { nas atividades de ensino, } \\
\text { pesquisa, extensão e/ou } \\
\text { inovação; }\end{array}$ & $\begin{array}{l}\text { e) Participação no } \\
\text { desenvolvimento de projetos } \\
\text { e/ou práticas pedagógicas de } \\
\text { reconhecida relevância; }\end{array}$ & $\begin{array}{l}\text { e) Atuação em atividades de } \\
\text { assistência técnica nacional } \\
\text { e/ou internacional; }\end{array}$ \\
\hline
\end{tabular}




\begin{tabular}{|l|l|l|}
\hline $\begin{array}{l}\text { f) Atuação na gestão } \\
\text { acadêmica e institucional, } \\
\text { contemplando o impacto } \\
\text { de suas ações nas demais } \\
\text { diretrizes dispostas para } \\
\text { todos os níveis do RSC; }\end{array}$ & $\begin{array}{l}\text { f) Participação na } \\
\text { organização de eventos } \\
\text { científicos, tecnológicos, } \\
\text { esportivos, sociais e/ou } \\
\text { culturais; }\end{array}$ & $\begin{array}{l}\text { f) Produção acadêmica e/ou } \\
\text { tecnológica, nas atividades } \\
\text { de ensino, pesquisa, extensão } \\
\text { e/ou inovação. }\end{array}$ \\
\hline $\begin{array}{l}\text { g) Participação em processos } \\
\text { seletivos, em bancas de } \\
\text { avaliação acadêmica e/ou de } \\
\text { concursos. }\end{array}$ & $\begin{array}{l}\text { g) Outras pós-graduações } \\
\text { lato sensu, na área de } \\
\text { interesse, além daquela que } \\
\text { o habilita e define o nível de } \\
\text { RSC pretendido, no âmbito } \\
\text { do plano de qualificação } \\
\text { institucional. }\end{array}$ & $\begin{array}{l}\text { g) Outras pós-graduações } \\
\text { stricto sensu, na área de } \\
\text { interesse, além daquela que } \\
\text { o habilita e define o nível de } \\
\text { RSC pretendido, no âmbito } \\
\text { do plano de qualificação } \\
\text { institucional; }\end{array}$ \\
\hline $\begin{array}{l}\text { h) Outras graduaçães, na } \\
\text { área de interesse, além } \\
\text { daquela que o habilita } \\
\text { e define o nível de RSC } \\
\text { pretendido, no âmbito } \\
\text { do plano de qualificação } \\
\text { institucional. }\end{array}$ & & \\
\hline
\end{tabular}

Fonte: BRASIL, 2014b.

A Resolução define, ainda, que as atividades dos docentes serão avaliadas por meio de análise de relatório contendo documentação que prove a realização das mesmas ou, quando se tratar de atividades realizadas antes de $1^{\circ}$ de março de 2013 , por meio de memorial descritivo elaborado pelo docente e contendo a descrição detalhada de sua trajetória profissional e acadêmica. Destacamos aqui a ausência da previsão de uma forma de avaliação que se aproxime do desenvolvimento da atividade de trabalho docente no curso de sua ação, prevalecendo a avaliação por meio da análise de documentos.

No que diz respeito aos parâmetros de avaliação, sua elaboração é competência de cada uma das instituições federais de ensino, que devem determiná-los por meio de regulamento interno, considerando as especificidades institucionais. Uma vez elaborados, os regulamentos devem ser submetidos à avaliação do Conselho Permanente de Reconhecimento de Saberes e Competências e somente podem ser publicados após sua aprovação.

Para ponderar sobre a forma como essa regulamentação é colocada em prática nas Instituições Federais de Ensino, realizamos uma aproximação do processo de Reconhecimento de Saberes e Competências no Centro Federal de Educação Tecnológica de Minas Gerais (CEFET-MG). Por meio da análise de documentos disponibilizados pela instituição, problematizamos a institucionalização do RSC no CEFET-MG. 


\section{RECONHECIMENTO DE SABERES E COMPETÊNCIAS NO CEFET-MG}

\subsection{SOBRE $O$ CEFET-MG}

O CEFET-MG, atualmente, possui 11 campi, sendo quatro localizados na região metropolitana de Belo Horizonte e sete distribuídos entre as cidades de Araxá, Curvelo, Divinópolis, Leopoldina, Nepomuceno, Timóteo, Varginha. A instituição oferta cursos técnicos nas modalidades integrada, concomitante e subsequente, além de cursos superiores e de pós-graduação. No total são ofertados 93 cursos do ensino técnico, 19 cursos de graduação e 16 cursos de pós-graduação, divididos entre especialização lato sensu, mestrado e doutorado (CEFET-MG, 2015).

Enquanto Instituição Federal de Ensino, o CEFET-MG emprega docentes das carreiras de Magistério Superior e do Ensino Básico, Técnico e Tecnológico, sendo 68 docentes inseridos na primeira carreira e 856 docentes da carreira EBTT. Ressaltamos que essa divisão na carreira não implica na limitação da atuação do docente a um só nível de ensino, sendo que os professores de ambas as carreiras podem atuar tanto no ensino superior quanto no ensino médio.

Ao todo, o CEFET-MG possui 924 professores efetivos, sendo que destes 396 são doutores, 456 são mestres, 20 são especialistas, 12 possuem o título de aperfeiçoamento e 40 são graduados. ${ }^{3} \mathrm{Na}$ tabela 2 apresentamos a titulação máxima dos docentes do CEFET-MG, de acordo com a unidade de ensino.

Tabela 2. Quantidade de docentes por formação e unidade do CEFET-MG

\begin{tabular}{|l|c|c|c|c|c|}
\hline \multicolumn{1}{|c|}{$\begin{array}{c}\text { Titulaçãol } \\
\text { Unidade }\end{array}$} & Doutores & Mestres & Especializados & Aperfeiçoados & Graduados \\
\hline Araxá & 26 & 29 & 4 & 6 & 0 \\
\hline Campus I - BH & 169 & 157 & 4 & 0 & 26 \\
\hline Campus II - BH & 115 & 60 & 6 & 0 & 2 \\
\hline Contagem & 6 & 22 & 0 & 1 & 0 \\
\hline Curvelo & 10 & 29 & 0 & 1 & 0 \\
\hline Divinópolis & 17 & 34 & 1 & 0 & 5 \\
\hline Leopoldina & 13 & 35 & 3 & 0 & 7 \\
\hline Nepomuceno & 10 & 28 & 1 & 2 & 0 \\
\hline Timóteo & 16 & 33 & 0 & 1 & 0 \\
\hline Varginha & 14 & 29 & 1 & 1 & 0 \\
\hline \multicolumn{1}{|c|}{ Total } & 396 & 456 & 20 & 12 & 40 \\
\hline
\end{tabular}

Fonte: CEFET-MG, 2015. 
No que diz respeito ao RSC, até o final do ano de 2015, foram concedidos 484 RSCs, distribuídos da seguinte forma: 10 RSCs de nível I, 37 RSCs de nível II e 436 RSCs de nível III. É importante esclarecer aqui que o número de professores com RSC-II ultrapassa a quantidade de docentes com especialização da instituição, fato que pode ser explicado pelo tipo dos dados apresentados neste momento, pois, enquanto o número de docentes se refere a dezembro de 2015, os dados sobre a concessão de RSC diz respeito a todas as solicitações já aprovadas no âmbito da instituição, sendo que, em alguns casos, o docente pode ter se desligado da instituição posteriormente à concessão do RSC ou, devido à obtenção de nova titulação, solicitado RSC em outro nível.

Ao analisarmos os dados apresentados no ano de 2015 no que diz respeito aos docentes da instituição com RSC em relação à sua titulação máxima, verificamos que a concessão de RSC-I contempla somente $20 \%$ dos professores com graduação ou aperfeiçoamento. Em contraste, constatamos que $96 \%$ dos docentes com mestrado no CEFET-MG foram aprovados no processo de avaliação do RSC-III. A explicação para tal fato pode se relacionar ao ingresso na carreira de EBT'T de sujeitos graduados sem experiência docente ou acadêmica, inviabilizando, em um primeiro momento, a obtenção do RSC.

Os dados apresentados explicitam a grande abrangência do RSC no CEFET-MG, trazendo questionamentos sobre como se constituí o processo de reconhecimento de saberes e também sobre seu impacto na formação dos professores. Diante de tal realidade, faz-se necessário uma análise mais aprofundada sobre o processo de reconhecimento de saberes no CEFET-MG, bem como sobre a natureza dos saberes valorizados e o impacto dessa política para as instituições de ensino, em especial sobre o processo de qualificação acadêmica dos docentes.

\subsection{A PRÁTICA DO RSC NO CEFET-MG}

O Reconhecimento de Saberes e Competências no CEFET-MG foi regulamentado pela Resolução CD-019/14, de 10 de junho de 2014 (CEFET-MG, 2014). Em consonância com as determinações legais, a Resolução estabelece que os procedimentos para concessão de RSC aos docentes da instituição serão conduzidos por Comissão análoga à Comissão Permanente de Pessoal Docente (CPPD), composta por membros da CPPD pertencentes, exclusivamente, à carreira EBTT.

Para fazer jus ao RSC o docente deve protocolar a solicitação junto à CPPD, por meio do preenchimento de formulários específicos e apresentação da documentação comprobatória das atividades realizadas ao longo de sua vida. Além do formulário de solicitação, o 
docente deverá preencher um "relatório descritivo", informando as atividades realizadas ao longo de sua trajetória acadêmica, profissional e intelectual. Tal relatório deve conter:

[...] c) o itinerário de formação, aperfeiçoamento e titulação; d) a descrição da atuação docente; e) a indicação e descrição de produção acadêmica, técnicocientífica, literária, artística e/ou esportiva; f) descrição das atividades de prestação de serviços à comunidade; g) indicação e descrição de atividades de administração e/ou participação em colegiados e conselhos deliberativos, órgãos de classe ou outros; h) indicação de títulos, homenagens, prêmios e/ou aprovações em concursos; i) cópias de documentos que comprovem as atividades contidas no relatório descritivo, devidamente validadas pela Comissão análoga à CPPD; j) planilha de atividades e pontuação; k) quadro-síntese das atividades descritas no relatório [...] (CEFET-MG, 2014).

Assim como estabelecido na Portaria 491/2013, a avaliação do relatório descritivo é realizada por Comissão Especial composta por 04 (quatro) membros, sendo dois internos e dois externos a instituição. A constituição das Comissões Especiais é variável, uma vez que os avaliadores são escolhidos por meio de sorteio a partir dos docentes que compõem o Banco de Nacional de Avaliadores.

Toda avaliação é orientada por um sistema de pontuação estabelecido no âmbito da instituição. Os critérios de avaliação são elencados em uma planilha na qual constam o tipo da atividade, os fatores de pontuação e o valor máximo que poderá ser alcançado em cada atividade.

A descrição das atividades, denominadas de Diretrizes na Resolução CD-019/14, por sua vez, são subdivididas em ações específicas, relacionadas à diretriz em questão. Para exemplificar a constituição do processo avaliativo, apresentamos, no Quadro 2, as diretrizes para avaliação no RSC-II, com seu peso e as respectivas pontuações máximas. Já no quadro 3 são explicitadas as atuações avaliadas dentro da diretriz IV deste mesmo nível.

Quadro 2. Diretrizes para avaliação do RSC-II

\begin{tabular}{|l|c|c|}
\hline \multicolumn{1}{|c|}{ Diretrizes Reconhecimento de Saberes e Competências II } & Peso & $\begin{array}{c}\text { Pontuação } \\
\text { Máxima }\end{array}$ \\
\hline $\begin{array}{l}\text { I - Orientação do corpo discente em atividades de ensino, pesquisa, extensão, } \\
\text { e/ou inovação }\end{array}$ & 2 & 20 \\
\hline $\begin{array}{l}\text { II - Participação no desenvolvimento de protótipos, depósitos e/ou registros de } \\
\text { propriedade intelectual }\end{array}$ & 1 & 10 \\
\hline III - Participação em grupos de trabalho e oficinas institucionais & 2 & 20 \\
\hline $\begin{array}{l}\text { IV - Participação no desenvolvimento de projetos, de interesse institucional, de } \\
\text { ensino, pesquisa, extensão e/ou inovação }\end{array}$ & 2 & 20 \\
\hline
\end{tabular}




\begin{tabular}{|l|c|c|}
\hline $\begin{array}{l}\text { V - Participação no desenvolvimento de projetos e/ou práticas pedagógicas de } \\
\text { reconhecida relevância }\end{array}$ & 1 & 10 \\
\hline $\begin{array}{l}\text { VI - Participação na organização de eventos científicos, tecnológicos, esportivos, } \\
\text { sociais e/ou culturais }\end{array}$ & 1 & 10 \\
\hline $\begin{array}{l}\text { VII - Outras pós-graduações lato sensu, na área de interesse, além daquela que o } \\
\text { habilita e define o nível de RSC pretendido, no âmbito do plano de qualificação } \\
\text { institucional }\end{array}$ & 1 & 10 \\
\hline Subtotal & 10 & 100 \\
\hline
\end{tabular}

Fonte: CEFET-MG. Resolução CD-019/14, de 10 de junho de 2014

Quadro 3. Atuações avaliadas dentro da diretriz IV do RSC-II

\begin{tabular}{|c|c|c|c|c|c|c|c|}
\hline & $\begin{array}{c}\text { RECONHECIMENTO } \\
\text { DE SABERES E } \\
\text { COMPETÊNCIAS - RSC II }\end{array}$ & $\begin{array}{c}\text { Fator de } \\
\text { Pontuação }\end{array}$ & Unidade & $\begin{array}{l}\text { Quantidade } \\
\text { máxima }\end{array}$ & Quantidade & Pontuação & $\begin{array}{c}\text { Pontuação } \\
\text { Máxima }\end{array}$ \\
\hline & $\begin{array}{l}\text { IV - Participação no } \\
\text { desenvolvimento de } \\
\text { projetos, de interesse } \\
\text { institucional, de ensino, } \\
\text { pesquisa, extensão e/ou } \\
\text { inovação }\end{array}$ & & & & & & \\
\hline 1 & $\begin{array}{l}\text { Elaboração de projetos } \\
\text { de ensino, pesquisa, } \\
\text { inovação tecnológica ou } \\
\text { extensão }\end{array}$ & 10,00 & projeto & 2 & & 0 & 20 \\
\hline 2 & $\begin{array}{l}\text { Coordenação de projeto } \\
\text { de pesquisa, inovação } \\
\text { tecnológica ou extensão }\end{array}$ & 0,83 & $\begin{array}{l}\text { mês por } \\
\text { projeto }\end{array}$ & 24 & & 0 & 20 \\
\hline 3 & $\begin{array}{l}\text { Desenvolvimento } \\
\text { de projetos visando } \\
\text { a capacitação de } \\
\text { professores ou outros } \\
\text { profissionais }\end{array}$ & 0,83 & $\begin{array}{l}\text { mês por } \\
\text { projeto }\end{array}$ & 24 & & 0 & 20 \\
\hline 4 & $\begin{array}{l}\text { Atuação nas atividades } \\
\text { de ensino, pesquisa e } \\
\text { extensão e as atividades } \\
\text { inerentes ao exercício de } \\
\text { direção, assessoramento, } \\
\text { chefia, coordenação ou } \\
\text { assistência na própria } \\
\text { instituição, nos diversos } \\
\text { níveis e modalidades de } \\
\text { ensino }\end{array}$ & 0,21 & Mês & 96 & & 0 & 20 \\
\hline 5 & $\begin{array}{l}\text { Participação em projetos } \\
\text { de ensino, pesquisa, } \\
\text { inovação tecnológica ou } \\
\text { extensão }\end{array}$ & 0,56 & $\begin{array}{l}\text { mês por } \\
\text { projeto }\end{array}$ & 36 & & 0 & 20 \\
\hline
\end{tabular}

Fonte: CEFET-MG. Resolução CD-019/14, de 10 de junho de 2014 
O valor de cada diretriz pode variar entre 10 e 30, dependendo do peso que a instituição atribui a mesma, que pode variar entre 1 e 3 . Da mesma forma, a pontuação relacionada a cada atuação do docente também pode variar entre 10 e 30, contudo a soma das atuações deve respeitar o valor máximo da diretriz em questão. Por exemplo, o número máximo de projetos de pesquisa, ensino, extensão e inovação tecnológica (item I do Quadro 3) que podem ser reconhecidos para fins de obtenção do RSC II é de 2 projetos. Uma vez que o fator de pontuação é de 10 pontos por projeto, o valor máximo a ser alcançado pelo docente são 20 pontos. Tendo em vista que o valor máximo da diretriz IV é também de 20 pontos (ver Quadro 2), ao contemplar integralmente o item I desta diretriz, o docente já obteve toda a pontuação possível dentro desta diretriz, sendo que as outras atuações listadas neste âmbito podem ser desconsideradas no processo de avaliação.

Para fins de avaliação, o docente poderá pontuar em qualquer um dos níveis do RSC, e não somente no nível pretendido. Contudo, a pontuação máxima a ser alcançada em cada um dos níveis é de 100 pontos, ou seja, o maior valor que poderá ser atingido por um docente é de 300 pontos no total. Para a aprovação no RSC, o professor deverá conseguir no mínimo 50 pontos, em qualquer nível, mas é preciso que ele obtenha, obrigatoriamente, no mínimo 25 pontos no nível do RSC pretendido.

Essa definição de valores máximos a serem atingidos no reconhecimento de saberes nos coloca a questão sobre o efetivo reconhecimento de saberes docentes, pois a avaliação é limitada a contemplação da pontuação pré-definida, correndo-se o risco de ignorar grande parte dos saberes desenvolvidos pelos docentes dentro e fora da instituição de ensino. Tal como está sendo colocado em prática o processo de RSC no CEFET-MG constitui-se, na realidade, como uma análise da documentação comprobatória das atividades acadêmicas realizadas pelo docente ao longo de sua vida.

Nesse processo de avaliação, os saberes docentes construídos no curso da atividade de trabalho e os saberes da experiência, construídos ao longo da vida, são deixados de lado e não aparecem como elemento a ser avaliado. A avaliação de saberes dessa natureza, que são subjetivos e intrínsecos ao sujeito, exige uma aproximação do trabalhador, o que não acontece no processo de RSC, no qual não se prevê qualquer contato entre avaliado e avaliadores. Essa avaliação documental de atividades acadêmicas pouco diz sobre os saberes do sujeito e se constituí enquanto uma forma extremamente limitada de valorização da experiência, pois se restringe a experiências acadêmicas ou de pesquisa. Como ficaria, então, o reconhecimento de saberes de docentes experientes, mas que 
se dedicaram a desenvolver atividades de natureza diversa daquelas valorizadas em uma matriz de avaliação estática?

Por outro lado, a delimitação de mínimo de pontos a serem atingidos parece-nos extremamente baixa, considerando que a soma total dos pontos distribuídos no sistema de pontuação estabelecido pela instituição é de 2.400 pontos. Além disso, a definição de fatores pontuação e de pontuação máxima para cada uma das diretrizes avaliadas traz à tona a realização de um juízo de valor em relação às atividades que compõem a docência na educação profissional. Sob esse prisma, há um destaque para a valorização das atividades relacionadas à pesquisa, tais como a orientação de alunos, a participação em grupos de pesquisa e a produção acadêmica, em especial quando analisamos os parâmetros de avaliação dos RSCs de nível II e III.

A valorização da prática docente em sala de aula somente está presente no RSC de nível I, onde a atuação do docente em diferentes níveis e modalidades de ensino compõe uma diretriz avaliativa. Contudo, dentro dessa diretriz há uma valorização da docência nos cursos de pós-graduação, que possuem fator de pontuação de 0,50 por mês de ensino, enquanto a docência no ensino técnico apresenta um fator de pontuação de 0,20 por mês de ensino e a docência nos cursos de formação continuada ou no Programa Nacional de Integração da Educação Profissional com a Educação Básica na Modalidade de Educação de Jovens e Adultos (PROEJA) tem um fator de pontuação de 0,15 por mês de ensino. Nesse sentido, ao privilegiar determinado tipo de atividade em detrimento de outras que também fazem parte do trabalho docente, o RSC reforça e estimula a desvalorização de atividades ligadas à extensão e, sobretudo, ao ensino na Educação Básica.

\section{INICIATIVAS PARA O RECONHECIMENTO DE SABERES DOCENTE NO BRASIL}

A discussão sobre a necessidade de se criar dispositivos voltados para reconhecimento de saberes construídos na/pela experiência de trabalho no Brasil pode ser rastreada ao começo da década de 1970, quando se implementou o projeto 128 desenvolvido pelo Centro Interamericano de Investigação e Documentação sobre Formação Profissional. Contudo, o tema ganhou força a partir da década de 1990 com as exigências das normas ISO 9000 (qualidade) e ISO 14000 (ambiental) que vinculavam o reconhecimento/ certificação de conhecimentos dos trabalhadores à certificação de produtos e processos de trabalho. Desde então, verifica-se o surgimento de programas voltados para o reconhecimento de saberes 
e certificação profissional de trabalhadores em diferentes áreas, desenvolvidos por diferentes agentes sociais, tais como Organizações não-governamentais, sindicatos, empresas, etc. (LIMA, 2011).

No âmbito do trabalho docente, a questão do reconhecimento de saberes dos professores aparece nos textos legais elaborados a partir de 2012, abordando especificamente os professores que atuam no Ensino Básico, Técnico e Tecnológico. A Resolução CNE/ CEB n. 06, de 20 de setembro de 2012, que trata sobre as Diretrizes Curriculares Nacionais para Educação Profissional Técnica de Nível médio, estabelece, no artigo 40, novas exigências para a formação de professores na área e define que

A formação inicial para a docência na Educação Profissional Técnica de Nivel Médio realiza-se em cursos de graduação e programas de licenciatura ou outras formas, em consonância com a legislação e com normas específicas definidas pelo Conselho Nacional de Educação (BRASIL, 2012, grifo da autora).

Ao estabelecer demandas para a formação de professores do EBTT, a Resolução traz à tona a possibilidade de equiparação entre a licenciatura e o reconhecimento de saberes dos docentes já inseridos nessa modalidade de formação, estabelecendo que

$\int 2^{\circ}$ Aos professores graduados, não licenciados, em efetivo exercício na profissão docente ou aprovados em concurso público, é assegurado o direito de participar ou ter reconhecidos seus saberes profissionais em processos destinados à formação pedagógica ou à certificação da experiência docente, podendo ser considerado equivalente às licenciaturas: [...] II - excepcionalmente, na forma de reconhecimento total ou parcial dos saberes profissionais de docentes, com mais de 10 (dez) anos de efetivo exercício como professores da Educação Profissional, no âmbito da Rede CERTIFIC [...] (BRASIL, 2012).

Conforme apontado por Silva (2014), 54\% dos docentes atuando na educação profissional possuem bacharelado, formação em engenharia ou em outros cursos tecnológicos, sem apresentarem qualquer tipo de formação pedagógica. Assim, entendemos que é durante a atividade de trabalho, em confronto com a realidade da sala de aula, em um tempo e espaço específico, que o professor da educação profissional constrói seus saberes docentes. De acordo com Urbanetz (2012), durante a atividade de trabalho esses professores constroem "conhecimentos pedagógicos tácitos", que não possuem uma fundamentação teórica clara, mas que tornam possível a prática docente. Dessa forma, apesar de não aparecer como item de discussão no Parecer 11/2012, que respalda a Resolução CNE/CEB n. 06/2012, consideramos que a possibilidade de reconhecimento de saberes dos professores do EBT'T constitui-se enquanto um avanço no campo e valoriza a trajetória profissional desses docentes. 
A possibilidade de reconhecimento de saberes docentes por meio de programas da Rede Certific respalda também a reestruturação desta. Assim, no ano de 2014, a Portaria Interministerial 08/2014, amplia o escopo da Rede e estipula três tipos de certificações profissionais, a saber:

a) Certificação de qualificação profissional: correspondente a curso de formação inicial e continuada ou qualificação profissional constante do Catálogo Nacional de Cursos de Qualificação Profissional, ou equivalente, mantido pelo Ministério da Educação-MEC; b) Certificação técnica: correspondente a curso técnico de nível médio constante do Catálogo Nacional de Cursos Técnicos, mantido pelo MEC, para possuidores de certificado de conclusão do Ensino Médio; c) Certificação tecnológica: correspondente a curso superior de tecnologia constante do Catálogo Nacional de Cursos Superiores de Tecnologia, mantido pelo MEC, para possuidores de certificado de conclusão do Ensino Médio; d) Certificação docente da educação profissional: correspondente à licenciatura em educação profissional, prevista nas diretrizes curriculares para formação de professores da educação profissional e vinculada ao exercício profissional de professores com mais de 10 (dez) anos de efetivo exercício na educação profissional e tecnológica (BRASIL, 2014a).

A Resolução CEB/CNE n. 06/2012 institui, o ano de 2020, como prazo limite para o atendimento das exigências de formação colocadas pelo artigo 40, no entanto, dado as recentes mudanças na Rede Certific, não foi possível localizarmos ações voltadas para o desenvolvimento de atividades de certificação docente. Destacase que a ausência de oferta de programas de Rede não se limita a essa modalidade de certificação, sendo que, até o momento, somente o Instituto Federal de Santa Catarina parece estar desenvolvendo iniciativas visando à certificação de trabalhadores.

\section{SABERES E TRABALHO: O APORTE DA ERGOLOGIA}

Compreender o trabalho a partir do campo da ergologia requer considerá-lo como atividade humana, na qual homem e meio estabelecem uma relação dialética. Esse encontro entre o meio historicamente construído, com suas técnicas e seus objetivos, e o trabalhador com suas singularidades, valores, saberes e competências, é sempre em parte singular e requer do sujeito em questão mobilizar e construir saberes sobre o trabalho. Assim, para compreender a experiência de trabalho enquanto local de formação e produção de saber é preciso partir de seu entendimento como atividade bumana. De acordo com Schwartz, o trabalho enquanto atividade humana

[...] É uma dinâmica onde se operam 'micro-criações industriosas, transgressões', onde se constroem saberes específicos, ligações coletivas, onde se colocam à 
prova valores sociais e políticos na confrontação da atividade de trabalho com as normas antecedentes (SCHWARTZ apud CHARLOT, 2004, p. 18).

Essa concepção de trabalho rompe com o paradigma taylorista de produção, que apregoa que o trabalho pode ser completamente racionalizado e prescrito, excluindo-se dele qualquer aspecto de subjetividade do trabalhador, e traz à tona uma distinção fundamental entre trabalho prescrito e trabalho real. $\mathrm{O}$ primeiro, diz respeito às normas e protocolos fornecidos aos trabalhadores como forma de se alcançar determinado objetivo. Já o segundo diz respeito à forma como o trabalhador realiza seu trabalho cotidianamente, mobilizando seus saberes para atender às necessidades surgidas no ambiente de trabalho.

Ao propor uma aproximação do trabalho real Durrive e Schwartz (2007) explicitam que a atividade comporta variabilidades que as prescrições não são capazes de abarcar e que, portanto, precisam ser geridas pelo trabalhador no curso da ação. Reconhecese não só a existência de uma distância entre a prescrição e a realidade do trabalho, mas também que essa distância é sempre, em parte, imprevisível e singular. Nesse sentido, a atividade de trabalho se localiza em um tempo e espaço específico e requer que o trabalhador convoque seus saberes construídos ao longo da experiência para resolver os problemas do trabalho que "escapam" às normas.

No curso da atividade o trabalhador coloca para si novas normas para tratar de aspectos não previstos na dimensão protocolar do trabalho. Ao fazer isso o trabalhador recorre ao seu patrimônio, sua experiência, para estabelecer, mesmo que provisoriamente, estratégias para realização da atividade (SCHWARTZ, 2010). Constata-se, portanto, no bojo da análise da atividade um tipo de saber diferente do conceitual, que é criado na e pela experiência de trabalho.

Esse saber, denominado saber investido, é construído "[...] na experiência da gestão de toda a atividade de trabalho. E esta experiência é investida nesta situação única e histórica. Trata-se de um saber que está em aderência com a atividade. Ele não é formalizado e nem escrito em qualquer lugar" (TRINQUET, 2010, p. 101). É justamente por estar em "aderência" com a atividade que o saber investido não é facilmente verbalizado ou constatado. O saber investido está no corpo-si, uma "entidade" que "atravessa tanto o intelectual, o cultural, quanto o fisiológico, o muscular, o sistema nervoso" (DURRIVE; SCHWARTZ, 2007 , p. 44) e que remete a um sujeito que não é nem completamente consciente nem inconsciente de sua ação.

A noção de saber investido se afasta de uma concepção de saber externo ao homem, tal como colocado pelos saberes constituídos ou acadêmicos. Estes estão em "desaderência" com a atividade, são 
genéricos e generalizáveis (TRINQUET, 2010; SCHWARTZ, 2010). Os saberes constituidos lidam com a dimensão protocolar do trabalho e são incapazes de abranger todas as dimensões da atividade de trabalho. Apesar de localizá-los em polos opostos, Trinquet (2010) afirma que os saberes investidos e constituídos são complementares. Dessa forma, eles constituem os dois lados de toda atividade de trabalho e precisam ser associados para conseguir se analisar uma situação particular de trabalho.

Uma vez admitido que o trabalho não é somente prescrição e que para o sucesso da produção o trabalhador precisa mobilizar sua experiência para fazer (micro)gestões e renormalizações na atividade, os saberes investidos vêm sendo cada vez mais valorizados. Nesse contexto, discussões sobre o reconhecimento de saberes vêm ganhando espaço tanto no âmbito da gestão do trabalho quanto nos programas de aprendizagem ao longo da vida (LIMA et al., 2013; LIMA, 2015).

Ao tratar especificamente sobre as estratégias de reconhecimento de saberes para a formação de adultos, Alcoforado (2008, p. 29) coloca que

[...] uma das aspirações centrais da educação e da formação de adultos, que se vinha manifestando desde o século XIX, mas que assume incontornável importância neste período em concreto, relacionou-se com a necessidade de encontrar metodologias credíveis de valorização e reconhecimento social das aprendizagens resultantes de atividades educativas não formais e informais [dentre elas o trabalho], procurando resolver a difícil equação da tradução dos diferentes tipos de saberes, criando condições efetivas para a sua equivalência formal. (ALCOFORADO, 2008, p. 29)

Contudo, os saberes investidos não são facilmente identificáveis, pois eles emergem na atividade e exige-se, então, uma aproximação do trabalho real para tentar compreender como o trabalhador mobiliza seus conhecimentos, experiências e valores para preencher o "vazio das normas". ${ }^{4}$ Ademais, segundo Schwartz (2010, p. 36), "[...] por detrás desse consenso mais ou menos adquirido quanto ao reconhecimento da experiência na atividade do trabalho, se colocam um ou vários problemas muito complicados e que questionam as estratégias de formação".

Para Schwartz (2010) a ponderação sobre o papel formador da experiência passa pela reflexão sobre o conceito de experiência; sobre a possibilidade de articulação entre os saberes constituídos e os saberes investidos; e sobre como ela "existe" em nossa cabeça e nosso corpo. Assim sendo, o reconhecimento de saberes construídos na e pela experiência não é tarefa fácil e coloca questões sobre o que é e quem faz a experiência, e como se pode identificar, sistematizar e transferir esses saberes que estão imbricados no corpo-si. 


\section{BREVE PANORAMA SOBRE OS SABERES DOCENTES}

Partindo do ponto de vista da atividade, tal como proposto pela ergologia, entende-se que o trabalho docente é local de articulação entre saberes investidos e saberes constituídos para realização da prática profissional. Nesse sentido, a prática docente pressupõe a (re)elaboração de saberes teóricos, estes vinculados à realização de cursos de formação inicial e continuada, confrontados com a realidade singular de cada sala de aula, cada aluno e cada conteúdo ensinado. Compreende-se, portanto, que "a formação pode antecipar tendencialmente as situações de trabalho, mas é atuando que o indivíduo mobiliza seu conhecimento, sua experiência e o conjunto das práticas necessárias à realização do trabalho" (CUNHA, 2005b, p.2).

Constata-se um crescimento de pesquisas que procuram se aproximar do exercício da docência para compreender sua natureza específica e que desvelam a existência de diversos saberes implicados nessa prática profissional (CUNHA, 2005A; MONTEIRO, 2001; CUNHA; ALVES, 2012; PENA, 2014). Nesse contexto, emerge a noção de "saber docente", categoria que

[...] permite focalizar as relações dos professores com os saberes que dominam para poder ensinar e aqueles que ensinam, sob uma nova ótica, ou seja, mediadas por e criadoras de saberes práticos, que passam a ser considerados fundamentais para a configuração da identidade e competência profissionais (MONTEIRO, 2001, p.123)

Apesar de terem como pano de fundo a problemática entre formação e prática de ensino, os estudos nessa área possuem abordagens teórico-metodológicas distintas. Sem pretensão de esgotar as discussões sobre o tema, destacam-se as contribuições de Tardif (2002), Schön (1992) e Therrien (2001) para esse campo (CUNHA, 2005A; MONTEIRO, 2001; CUNHA; ALVES, 2012; PENA, 2014).

Schön (1992) aponta que os saberes dos professores se (re) criam durante a ação. Em um processo denominado reflexãona-ação, o autor considera que os professores ponderam sobre suas práticas no curso do ato de ensinar e criam estratégias para viabilizar a aprendizagem pelo aluno. De acordo com Cunha (2005a, p.2), as hipóteses de Schön consideram que esses saberes são "[...] construídos na prática cotidiana, são pessoais, tácitos, não sistemáticos, espontâneos, intuitivos, experimentais [...]". Assim sendo, o autor propõe uma formação profissional calcada na prática reflexiva.

Já Therrien (2001) discute o saber docente a partir das necessidades colocada aos professores de "agir em situação", levando em consideração a formação e a prática de professores no Brasil. 
Esse autor procura identificar e compreender as especificidades dos sujeitos dessa prática, aprofundando-se sobre a natureza do saber da experiência docente e sua função na ação. De acordo com Therrien e Loiola (2001, p.148),

À luz de abordagens que o concebem como prática situada, contextualizada,
o trabalho docente revela-se fruto de processo que envolve múltiplos saberes
oriundos da formação, da área disciplinar, do currículo, da experiência, da prática
social, e da cultura, entre outros. Trata-se de uma atividade regida por uma
racionalidade prática que se apóia em valores, em teorias, em experiências e em
elementos contextuais para justificar as tomadas de decisão na gestão da sala de
aula. (THERRIEN; LOIOLA, 2001, p.148)

Baseando-se no conceito de aprendizagem situada de Jean Lave, ${ }^{5}$ considera-se que o saber-fazer de professores se inserem em um campo complexo de inter-relações (na sala de aula, na escola, na comunidade) que atuam como elementos estruturantes de sua ação. $\mathrm{O}$ autor se fundamenta também em Schön para defender que a ação do professor é orientada por uma prática reflexiva no curso das situações de trabalho. Dessa maneira, o autor estabelece uma ligação entre atividade e situação para a construção dos saberes docentes.

Tardif (2002) apresenta uma importante contribuição para os estudos sobre os saberes docentes. De acordo com Cunha e Alves (2012, p. 21), o autor "[...] parece desenvolver um quadro analítico mais amplo entre as pesquisas sobre os saberes docentes, sendo possivelmente no campo um autor maior". Isso porque Tardif, apesar de privilegiar a análise do trabalho docente fundamentado na teoria da ação, o aborda também a partir de perspectiva de disciplinas que estudam o trabalho, tais como a sociologia do trabalho e das profissões e a ergonomia, e as articula com pesquisas elaboradas no campo da educação.

Para Tardif (2002) o saber do docente é plural, formado pela combinação de saberes profissionais, disciplinares, curriculares e experienciais. Os três primeiros saberes situam-se em uma posição de exterioridade em relação à prática docente, pois são definidos pelo Estado e pelos grupos produtores de "saberes sociais". Os saberes experienciais, por sua vez, têm origem na prática cotidiana dos professores em confronto com as condições reais de trabalho e constituem os fundamentos de sua competência. O autor entende que, diferentemente do que se passa no campo de pesquisas científicas, no cotidiano do trabalho os professores se inserem em contextos com múltiplas interações que se dão em "[...] situações concretas que não passíveis de definições acabadas e que exigem improvisação e habilidade pessoal, bem como a capacidade de enfrentar situações mais ou menos transitórias e variáveis" (idem, p.49). 
Tardif (2002, p. 255) propõe, então, uma epistemologia da prática profissional e a define como "[...] estudo do conjunto dos saberes $^{6}$ utilizados realmente pelos profissionais em seu espaço de trabalho cotidiano para desempenhar todas as suas tarefas". Nesse sentido, o autor caracteriza saberes profissionais como saberes da ação, que são do trabalho e acontecem no trabalho, e que, portanto, só têm sentido se analisados nas situações de trabalho real.

Nessa acepção, os trabalhos de Tardif se aproximam da perspectiva da ergologia e da ergonomia da atividade sobre a compreensão de saberes da experiência. No entanto, conforme afirma Cunha (2005a), as bases desse autor nas teorias da ação, o distanciam de um entendimento mais profundo do trabalho como atividade humana.

No que diz respeito aos saberes dos professores do Ensino Básico, Técnico e Tecnológico, constata-se que estes desenvolvem no curso de seu trabalho "conhecimentos pedagógicos tácitos" ligados às experiências cotidianas de trabalho, sem que possuam qualquer explicitação teórica clara (URBANETZ, 2012). Esse desenvolvimento de "conhecimentos pedagógicos tácitos" se relaciona com o fato desses profissionais, ao contrário do que acontece com os docentes da educação básica geral, não precisarem dispor de formação pedagógica para ingresso na profissão. Nesse sentido, de acordo com Oliveira (2006, p. 8), "o professor do ensino técnico não é concebido como um profissional da área de educação, mas um profissional de outra área e que nela também leciona”.

Contudo, a especificidade do trabalho dos professores do EBTT vai além das exigências de formação, e se relaciona também o tipo de conteúdo ensinado. Nesse contexto, coloca-se em questão não só o ensino de procedimentos técnicos ligados ao exercício profissional, mas também a necessidade de o docente desenvolver estratégias pedagógicas capazes de contribuir para a articulação entre o conhecimento teórico e aprendizagem prática, calcados em uma perspectiva crítica que viabilize a reflexão do aluno sobre o contexto de trabalho e as relações sociais que aí se desenvolvem (PENA, 2014). Assim sendo, a prática dos professores do EBTT se relaciona com os estudos desenvolvidos sobre saberes docentes no âmbito geral, mas apresentam especificidades que se ligam às exigências de formação desses profissionais, à natureza dessa modalidade de ensino, ao tipo de conteúdo, ao ambiente de trabalho e às formas de regulação do trabalho (OLIVEIRA, 2006; AUAREK, 2012; URBANETZ, 2012; PENA, 2014). 


\section{CONSIDERAÇÕES FINAIS}

Nesse trabalho buscamos problematizar como as ações o voltadas para o reconhecimento de saberes de professores do Ensino Básico, Técnico e Tecnológico vêm se corporificando nas políticas públicas brasileiras. Para realizarmos a discussão proposta, apresentamos como se constituem as políticas de reconhecimento de saberes desses professores no Brasil. Visando aprofundar nossa discussão, analisamos a forma como o processo de Reconhecimento de Saberes e Competências é realizado no CEFET-MG. Como pano de fundo, adotamos o aporte teórico da ergologia, para pesarmos o trabalho como encontro entre o trabalho real e prescrito, onde o trabalhador constrói novos saberes. Apresentamos também as discussões de alguns dos principais autores que tratam sobre os saberes docentes e as especificidades da docência no Ensino Básico, Técnico e Tecnológico.

Essa trajetória de discussão aponta para a complexidade dos saberes docentes, construídos, tal como aponta Tardif (2002), na confluência de saberes profissionais, disciplinares, curriculares e experienciais, mas, ao mesmo tempo, explicita a importância de tais saberes para as práticas docentes. A criação de uma política de reconhecimento de saberes desses profissionais vem, dessa forma, para valorizar os saberes da prática, mas coloca em questão os limites e possibilidades de avaliação e reconhecimento desses saberes. As políticas públicas brasileiras com tal finalidade ainda são recentes, o que impossibilita uma análise aprofundada sobre o processo de reconhecimento de saberes em si, mas a confrontação entre o panorama das orientações legais e os estudos do campo da ergologia e do trabalho docente aponta para questões importantes a ser consideradas durante o processo de avaliação.

Em uma primeira análise do processo de RSC no CEFETMG, constatamos que, em consonância com o que dispõe a legislação, a avaliação dos "saberes e competências" dos professores foca-se na análise de documentação que comprova a realização de determinada atividade pelo professor. Dentro desse sistema de avaliação, a atribuição de pontos para cada tipo de atuação, explicita a valorização das atividades de pesquisas em detrimento, especialmente, das atividades de ensino, que só aparecem nas diretrizes de avaliação do RSC-I. O mesmo acontece quando verificamos que a valorização da experiência profissional do professor antes de ingresso na instituição de ensino, enquanto profissional em sua área de formação, não faz parte das diretrizes de avaliação do RSC em nenhum de seus níveis. 
Nesse sentido, o RSC, além de reforçar, potencialmente, o desinteresse dos professores em se envolver nas atividades de ensino, traz à tona o que consideramos como um novo perfil de docente da educação profissional. Se anteriormente, o professor da educação profissional era selecionado e valorizado por sua experiência profissional fora da escola - ou seja, tomado como um profissional de outra área e que também leciona -, agora ele é valorizado por sua experiência enquanto pesquisador da área.

Nesse mesmo escopo, há uma preocupação por parte dos atores institucionais de que o RSC gere um desestímulo nos docentes do EBTT para realização de cursos de pós-graduação nos níveis de mestrado e doutorado. Contudo, os dados disponibilizados pelo CEFET-MG acerca da formação acadêmica de seus professores demonstram um crescimento no nível de qualificação dos docentes e também de ingresso nos cursos de pós-graduação. No ano de 2014, por exemplo, a instituição contava com 355 docentes com título de doutor, já em 2015 esse número passou para 396. Assim, em um primeiro momento, não se pode dizer que o RSC interfere na qualificação dos docentes do EBT'T na instituição.

A aproximação do processo de RSC no CEFET-MG indica a necessidade de se problematizar o que está realmente sendo valorizado e quais saberes docentes estão sendo realmente reconhecidos. Do ponto de vista da ergologia, os saberes construídos no/pelo trabalho estão diretamente ligados à atividade e, assim sendo, somente podem ser analisados a partir de uma aproximação do trabalhador. A realização de uma avaliação por meio de análise de documentos e com uma matriz estática que se pauta no desenvolvimento de atividades de cunho acadêmico, pouco contribui para a valorização dos saberes dos docentes que possuem experiência de trabalho, mas que optaram por desenvolver atividades diferentes daquelas elencadas no referencial de avaliação. A partir dessa perspectiva, abrem-se questionamentos quanto às possibilidades de avaliação dos saberes dos professores desvinculados da prática docente e sobre qual seria uma forma mais coerente de avaliação.

Nesse contexto, é necessário refletir sobre quais são os saberes que estão sendo valorizados durante o processo de certificação e quais são aqueles deixados em segundo plano e quais os motivos para tal. É preciso nos atentar para que o processo de avaliação desses saberes não se constitua em mais uma atividade burocrática realizada no âmbito das instituições de ensino, mas sim como um processo de valorização dos saberes docentes. 
Por outro lado, apesar de apresentar problemas em sua forma atual, o desenvolvimento de políticas voltadas para o reconhecimento de saberes dos professores da educação profissional constitui-se como um avanço para as discussões acerca do caráter formador da experiência e da aprendizagem ao longo da vida. No âmbito legal, ao se considerar que o reconhecimento de saberes de professores dessa modalidade pode ser equiparado à obtenção do título de licenciado, reconhece-se que a experiência é formadora e que os saberes construídos no seu curso fundamentam uma boa prática docente. No entanto, chamamos atenção, novamente, para o problema de se tentar recortar quais experiências devem ser valorizadas, elaborandose uma matriz de avaliação fechada, que desconsidera que os sujeitos são formados por diferentes experiências que não podem ser elencadas igualmente para todos.

\section{REFERÊNCIAS}

ALCOFORADO, J. L. M. Competências, cidadania e profissionalidade: limites e desafios para a construção de um modelo português de educação e formação de adultos. 2008. 460f. Tese (Doutorado em Ciências da Educação)- Faculdade de Psicologia e de Ciências da Educação, Universidade de Coimbra, Coimbra, 2008.

AUAREK, W. M. F. Educação profissional técnica de nível médio: circulação de saberes e valores na atividade de trabalho docente. 2012. 266f. Tese (Doutorado em Educação) Faculdade de Educação, UFMG, Belo Horizonte, 2012.

BRASIL. Congresso Nacional. Lei no. 9.394, de 20 de dezembro de 1996. Estabelece as Diretrizes e Bases da Educação Nacional. Diário Oficial da República Federativa do Brasil, Brasília, DF, 23 dez, 1996. Seção 1, v. 248, p. 27833.

BRASIL. Conselho Nacional de Educação. Resolução CNE/CEB n. 06, de 20 de setembro de 2012. Define Diretrizes Curriculares Nacionais para a Educação Profissional Técnica de Nível Médio. Diário Oficial da República Federativa do Brasil, Brasília, DF, 21 set. 2012. Seção 1, v. 184, p. 22. 2012.

BRASIL. Ministério da Educação. Portaria Interministerial MEC/MTE nº 05, de 25 de abril de 2014. Dispõe sobre a reorganização da Rede Nacional de Certificação Profissional - Rede Certific. Diário Oficial da República Federativa do Brasil, Brasília, DF, 02 mai. 2014. v. 82, p. 14. 2014a.

BRASIL. Secretaria de Educação Profissional e Tecnológica. Resolução n. 01, de 20 de fevereiro de 2014. Diário Oficial da República Federativa do Brasil, Brasília, DF, 21 de fev. 2014, v. 37, p. 29. 2014b.

BJØRNÅVOLD, J.; LE MOUILLOUR, I. Learning outcomes in validation and credit systems. European journal of vocational training, Salonica, v. 48, n. 3, p. 27 - 47, 2009.

CEFET-MG. Resolução CD-019/14, de 10 de junho de 2014. Dispõe sobre a regulamentação da avaliação e fluxo de procedimentos para a concessão do Reconhecimento 
de Saberes e Competências (RSC) aos docentes pertencentes à Carreira de Magistério do Ensino Básico, Técnico e Tecnológico do Centro Federal de Educação Tecnológica de Minas Gerais. Conselho Diretor. 2014.

CEFET-MG. Relatório de Gestão do Exercício de 2015. Belo Horizonte: CEFET-MG, 2015. Disponível em: http://cefetmg.br/galeria/indicadores/relatorio_gestao/CEFET_ MG_26257_Relatorio_de_Gestao_2015_V3.pdf. Acesso em: 03 dez. 2016.

CHARLOT, B. Educação, trabalho: Problemáticas contemporâneas convergentes. Educação, sociedade e cultura, Porto, n. 22, p. 9-25, 2004.

CUNHA, D. M. Atividade humana e produção de saberes no trabalho docente. In. ENCONTRO NACIONAL DE DIDÁTICA E PRÁTICA DE ENSINO, 13, 2005, Pernambuco. Anais... Pernambuco: ENDIPE, 2005a. s/p. Disponível em: http://sites. univ-provence.fr/ergolog/html/ergologia_franco-luzitana_fichiers/CUNHA_Atividade. pdf. Acesso em: 01 ago. 2015.

CUNHA, D. Saberes, qualificações e competências: qualidades humanas na atividade de trabalho. In. REUNIÃO ANUAL DA ASSOCIAÇÃO NACIONAL DE PÓSGRADUAÇÃO E PESQUISA EM EDUCAÇÃO, 28, 2005, Caxambu. Anais... Caxambu: ANPEd, 2005b, s/p.

CUNHA, D. M.; ALVES, W. F. Da atividade humana entre paideia e politeia: saberes, valores e trabalho docente. Educação em revista, Belo Horizonte, v. 28, n. 2, p. 17-34, 2012.

DURRIVE, L.; SCHWARTZ, Y. Trabalho e Ergologia: conversas sobre a atividade humana. Niterói: Eduff, 2007.

JARVIS, P. From adult education to lifelong learning and beyond. Comparative Education, v. 50 , n. 1 , p. $45-57,2014$.

LIMA, N. V. Análise do sistema de reconhecimento de saberes e certificação profissional brasileiro: um olhar sobre a Rede CERTIFIC. Monografia (Graduação em Pedagogia) - Faculdade de Educação, UFMG, Belo Horizonte, 2011.

LIMA, N. V.; PETRUS, Â.; M. F.; CUNHA, D. M.. A produção de saberes no trabalho: qual o valor dos saberes investidos? Revista Pedagógica, Chapecó, v. 15, n. 31, p. 321-334, 2013.

LIMA, N. V.; CUNHA, D. M. Políticas de certificação profissional na Inglaterra: dispositivos de reconhecimento de saberes do trabalho. Revista da ABET, v. 13, n. 1, 2014.

LIMA, N. V. Reconhecimento de saberes do trabalho e certificação profissional: a experiência da Inglaterra. 2015, 289f. Dissertação (Mestrado em Educação) - Faculdade de Educação, UFMG, Belo Horizonte, 2015.

MONTEIRO, A. M. F. da C. Professores: entre saberes e práticas. Educação \& Sociedade, Campinas, v.22, n.74, p.121-142, 2001.

MORAES, C. S.; NETO, S. L. Educação, formação profissional e certificação de conhecimentos: considerações sobre uma política pública de certificação profissional. Educação e Sociedade, Campinas, v. 26, n. 93, p. 1435-1469, set./dez. 2005.

OLIVEIRA, M. R. N. S. Formação e profissionalização dos professores do ensino técnico. Educação e Tecnologia, Belo Horizonte, v. 11, n.2, p. 03-09, jul./dez. 2006.

PENA, G. A. C. Docência na Educação Profissional e Tecnológica: conhecimentos, práticas e desafios de professores de cursos técnicos na Rede Federal. 2014. 290f. Tese (Doutorado em Educação) - Faculdade de Educação, UFMG, 2014. 
SCHÖN, D. Formar professores como profissionais reflexivos: In. NÓVOA, Antônio (org.). Os professores e sua formação. Lisboa: Nova Enciclopédia, 1992.

SCHWARTZ, Y. Os ingredientes da competência: um exercício necessário para uma questão insolúvel. Educação \& Sociedade, v. 19, n. 65, p. 101-140, 1998.

SCHWARTZ, Y. A experiência é formadora? Educação \& Realidade, Porto Alegre, v. 35, n. 1, p. 35-48, 2010.

SILVA, F. L. G. Identidade profissional dos professores da Educação Profissional Técnica de Nível Médio no Brasil e em Santa Catarina: desafios para a sua formação. 2014. 237f. Tese (Doutorado em educação) - Universidade Federal de Santa Catarina. Santa Catariana, 2014.

TARDIF, M. Saberes docentes e formação profissional. Petrópolis: Vozes, 2002.

THERRIEN, J.; LOIOLA, F. A. Experiência e competência no ensino: pistas de reflexões sobre a natureza do saber-ensinar na perspectiva da ergonomia do trabalho docente. Educação \& Sociedade, vol.22, n.74, p. 143-160, 2001.

TRINQUET, P. Trabalho e educação: o método ergológico. Revista HISTEDBR, Campinas, número especial, p. 93-113, ago.2010.

UNESCO. Declaração de Hamburgo: agenda para o futuro. In. CONFERÊNCIA INTERNACIONAL SOBRE A EDUCAÇÃO DE ADULTOS, 5, 1999, Hamburgo. Declaração... Brasília: SESI/UNESCO, 1999, 67p.

URBANETZ, S. T. Uma ilustre desconhecida: a formação docente para a educação profissional. Rev. Diálogo Educ., Curitiba, v. 12, n. 37, p. 863-883, set./dez. 2012.

YOUNG, M; ALLAIS, S. M. Implementing National Qualification Frameworks across five continents. Londres: Routledge, 2013.

\section{NOTAS}

${ }^{1}$ De acordo com Alcoforado (2008, p. 36), as Conferências Internacionais sobre Educação de Adultos "surgiram em conjunto com outras reuniões temáticas, também sob a égide da UNESCO, acabaram por se constituir como espaços incontornáveis para perceber a evolução mundial deste campo, ao longo das últimas décadas".

${ }^{2}$ A carreira de magistério no Ensino Básico, Técnico e Tecnológico foi instituída em 2008 , por meio da lei $\mathrm{n}^{\circ} 11.784$, de 22 de setembro de 2008 e destina-se aos profissionais habilitados em atividades acadêmicas próprias do pessoal docente no âmbito da educação básica e da educação profissional e tecnológica.

${ }^{3}$ Dados referentes ao ano de 2015.

${ }^{4}$ De acordo com Durrive e Schwartz (2007) adota a noção de "vazio das normas" para tratar sobre os aspectos não antecipáveis da atividade, que escapam à prescrição, e que devem ser preenchidos pelo trabalhador.

${ }^{5}$ Cf. LAVE, Jean; WENGER, Etienne. Situated learning: Legitimate peripheral participation. Cambridge: Cambridge University Press, 1991.

${ }^{6} \mathrm{O}$ entendimento do autor do que são "saberes" engloba conhecimentos, competências, habilidades, aptidões e atitudes. 
Submetido: 22/03/2017

Aprovado: 30/05/2017

Contato:

Universidade Federal de Minas Gerais (UFMG) FaE - Faculdade de Educação Av. Presidente Antônio Carlos, no 6627 - Pampulha, Belo Horizonte |MG | Brasil CEP 31.270-901 